\title{
Physicochemical Simulation of the Qualitative and Quantitative Phase Composition of Iron Ores
}

\author{
Anastasiya V. Oshchepkova ${ }^{a, b}$, Victor M. Chubarov*a, \\ Valery A. Bychinsky ${ }^{\mathrm{a}, \mathrm{b}}$ and Ekaterina V. Kaneva ${ }^{\mathrm{a}}$ \\ ${ }^{a}$ Vinogradov Institute of Geochemistry $S B R A S$ \\ Irkutsk, Russian Federation \\ ${ }^{b}$ Irkutsk State University \\ Irkutsk, Russian Federation
}

Received 29.10.2019, received in revised form 10.11.2019, accepted 15.01.2020

\begin{abstract}
A method for mineral phases contents determination in iron ores based on mathematical simulation of physicochemical processes of ore formation in terms of data on the elemental composition of ores is proposed. The obtained results were compared with the phase composition of certified reference materials given in the certificates and results of qualitative analysis using X-ray powder diffraction method. Iron ores significantly vary in phase composition, however, the developed method allows quantifying the content of ore minerals, including minerals that cannot be detected by the X-ray powder diffraction method and can be used to determine the phase composition of ores in order to assess potential industrial significance.
\end{abstract}

Keywords: X-ray powder diffraction, physic-chemical modeling, iron ores.

Citation: Oshchepkova A.V., Chubarov V.M., Bychinsky V.A., Kaneva E.V. Physicochemical simulation of the qualitative and quantitative phase composition of iron ores, J. Sib. Fed. Univ. Chem., 2020, 13(1), 65-77. DOI: 10.17516/1998-28360169

(C) Siberian Federal University. All rights reserved

This work is licensed under a Creative Commons Attribution-NonCommercial 4.0 International License (CC BY-NC 4.0).

* Corresponding author E-mail address: chubarov@igc.irk.ru 


\title{
Физико-химическое моделирование качественного \\ и количественного фазового состава железных руд
}

\author{
А.В. Ощепкова ${ }^{a, \tilde{\sigma}}$, В.М. Чубаров ${ }^{a}$, \\ В.А. Бычинский ${ }^{\mathbf{a}, \mathbf{0}}$, Е.В. Канева ${ }^{\mathrm{a}}$ \\ ${ }^{a}$ Институт геохимии им. А.П. Виноградова СО РАН \\ Российская Федераџия, Иркутск \\ ${ }^{\sigma}$ Иркутский государственный университет \\ Российская Федерация, Иркутск
}

Аннотация. Предложен способ определения содержания минеральных фаз в железных рудах на основе математической модели физико-химических процессов их образования, опирающейся на данные об элементном составе. Полученные результаты сопоставлены с приведенным в паспортах фазовым составом стандартных образцов и качественным рентгенофазовым анализом. Железные руды значительно варьируют по фазовому составу, однако разработанный метод позволяет количественно оценивать содержания рудных минералов, в том числе тех, которые не удается обнаружить методом рентгенофазового анализа, и может быть использован для определения фазового состава руд с целью оценки потенциальной промышленной значимости.

Ключевые слова: рентгенофазовый анализ, физико-химическое моделирование, железные руды.

Цитирование: Ощепкова, А.В. Физико-химическое моделирование качественного и количественного фазового состава железных руд / А.В. Ощепкова, В.М. Чубаров, В.А. Бычинский, Е.В. Канева // Журн. Сиб. федер. ун-та. Химия, 2020. 13(1). C. $65-77$. DOI: $10.17516 / 1998-2836-0169$

\section{Введение}

Оценка промышленной значимости железорудных месторождений требует точного определения фазового состава руд. При этом месторождения могут формироваться как в эндогенных, так и в экзогенных геологических процессах. Выделяют магматические, скарновые, карбонатитовые, метаморфогенные, вулконогенно-гидротермальные, осадочные железорудные месторождения и месторождения кор выветривания [1]. Такое разнообразие генетических типов предопределяет широкие вариации их минерального (фазового) и элементного состава. По основному рудному минералу выделяют несколько типов руд [2]. Красный железняк образован безводным оксидом железа $\mathrm{Fe}_{2} \mathrm{O}_{3}$ (гематит), бурый железняк - водными оксидами железа $\mathrm{Fe}_{2} \mathrm{O}_{3} \cdot \mathrm{nH}_{2} \mathrm{O}$ (гидрогетит, лимонит и др.), магнитный железняк - смешанным оксидом железа $\mathrm{Fe}_{3} \mathrm{O}_{4}$ (магнетитом), который представляет собой изоморфную смесь оксидов железа $\mathrm{FeO}$ и $\mathrm{Fe}_{2} \mathrm{O}_{3}$, либо, в случае замещения железа титаном, титаномагнетитом, шпатовый железняк - карбонатом железа $\mathrm{FeCO}_{3}$ (сидеритом). Другие распространенные соединения железа (пирит, марказит, пирротин) не могут рассматри-

$$
-66-
$$


ваться как полезные железорудные минералы, поскольку сера и мышьяк существенно понижают качество руды.

С задачей определения элементного состава железных руд успешно справляются как классические химические и физико-химические методы [3], так и современные физические методы анализа, в частности, метод рентгенофлуоресцентного анализа [4-8]. Основные физические методы определения фазового состава - рентгеновская порошковая дифракция [9] и электроннозондовый микроанализ [10]. Электронно-зондовый микроанализ требует специального приготовления исследуемого образца и позволяет оценивать химический состав частиц минеральных фаз, размеры которых более 1 мкм. Количественная оценка соотношения минеральных фаз затруднительна, поскольку предполагает трудоемкое и длительное измерение больших размеров поверхностей образцов. Метод рентгеновской порошковой дифракции идентифицирует только кристаллические минеральные фазы. Количественное определение минерального состава методом рентгеновской дифракции представляет собой сложную задачу, прежде всего из-за отсутствия стандартных образцов с аттестованным минеральным составом и неопределенности идентификации отдельных минералов в минеральных группах, а также сравнительно высоких пределов обнаружения. Установленная в межлабораторном эксперименте погрешность метода рентгеновской дифракции при определении минерального (фазового) состава искусственных смесей хорошо охарактеризованных минералов может быть менее 3 \% [11, 12], однако реальную погрешность анализа природных смесей установить затруднительно. Получение количественных данных о соотношениях фаз требует специального программного обеспечения и высокой квалификации аналитика и не всегда может быть реализовано при рутинном анализе. В том случае, когда в рудных объектах присутствуют рентгеноаморфные фазы, метод рентгеновской порошковой дифракции не может быть применен даже как качественный.

В данной работе предложен альтернативный способ определения фазового состава при помощи физико-химического моделирования, позволяющего методом минимизации энергии Гиббса [13] по химическому составу качественно оценить соотношение минеральных фаз.

\section{Объект исследования}

В качестве объектов для физико-химического моделирования минерального (фазового) состава выбраны следующие стандартные образцы железных руд: НФС-28 (Всероссийский институт минерального сырья, г. Москва), Р7г, Р9б, Р39 (Институт стандартных образцов, г. Екатеринбург), СО-20 («Западно-Сибирский испытательный центр», г. Новокузнецк), ОСО 181-89, ОСО 183-89, ОСО 184-89, 5403-90 (ТОО «Центргеоланалит», г. Караганда, Республика Казахстан), 46 и ЗД-1 (Бронницкая геолого-геохимическая экспедиция), в которых аттестованы содержания основных породообразующих элементов. Дополнительно было определено содержание двухвалентного железа (в пересчете на оксид $\mathrm{FeO}$ ) аттестованной методикой титриметрического анализа (НСАМ № 50-X), диоксида углерода $\left(\mathrm{CO}_{2}\right)$ методикой титриметрического анализа (НСАМ № 230-X), гигроскопической и связанной воды $\left(\mathrm{H}_{2} \mathrm{O}^{ \pm}\right)$- методикой гравиметрического анализа (НСАМ № 120-Х) [3]. Данные о соотношениях валентных форм железа необходимы для точного учета количества кислорода в модели, а содержание связанной воды необходимо для моделирования состава слоистых силикатов (хлоритов, слюд), содержащих ОН-группу в структуре минерала. Химический состав исследуемых стандартных образцов приведен в табл. 1.

$$
-67-
$$


Таблица 1. Химический состав стандартных образцов железных руд

Table 1. Composition of certified reference materials of iron ores

\begin{tabular}{|c|c|c|c|c|c|c|c|c|c|c|c|}
\hline & $4 б$ & $\begin{array}{c}\text { OCO } \\
181-89\end{array}$ & $\begin{array}{c}5403- \\
90\end{array}$ & P39 & $\begin{array}{c}\text { OCO } \\
184-89\end{array}$ & $\mathrm{CO}-20$ & $\mathrm{P} 7 \Gamma$ & $\begin{array}{c}\text { OCO } \\
183-89\end{array}$ & ЗД-1 & $\begin{array}{c}\text { НФC- } \\
28\end{array}$ & Р9б \\
\hline $\mathrm{SiO}_{2}$ & 14.37 & 6.11 & 7.14 & 49.10 & 7.99 & 28.16 & 13.75 & 41.56 & 17.48 & 0.58 & 2.29 \\
\hline $\mathrm{TiO}_{2}$ & 0.34 & 0.07 & 0.06 & 0.16 & 0.05 & 0.48 & 0.19 & 0.07 & $\mathrm{H} / \mathrm{a}$ & 0.03 & 0.03 \\
\hline $\mathrm{Al}_{2} \mathbf{O}_{3}$ & 4.22 & 1.18 & 0.73 & 3.92 & 1.01 & 7.43 & 4.75 & 1.66 & 1.09 & 0.33 & 0.64 \\
\hline $\mathrm{Fe}_{2} \mathrm{O}_{3}$ & 44.54 & 64.45 & 65.81 & 23.62 & 62.63 & 26.57 & 61.47 & 48.83 & 79.35 & 96.60 & 1.92 \\
\hline $\mathrm{FeO}$ & 20.33 & 23.55 & 21.74 & 14.96 & 20.34 & 9.60 & 0.53 & 1.32 & 0.86 & 0.84 & 41.13 \\
\hline MnO & 0.47 & 0.15 & 0.21 & 0.07 & 0.46 & 2.00 & 2.46 & 0.06 & 0.06 & 0.01 & 1.37 \\
\hline MgO & 5.13 & 0.74 & 0.65 & 1.97 & 0.22 & 3.31 & 0.75 & 0.08 & 0.04 & 0.02 & 10.90 \\
\hline $\mathrm{CaO}$ & 5.78 & 2.19 & 0.89 & 1.69 & 1.35 & 14.67 & 1.55 & $\mathrm{H} / \mathrm{a}$ & $\mathrm{H} / \mathrm{a}$ & 0.09 & 2.55 \\
\hline $\mathrm{Na}_{2} \mathrm{O}$ & $\mathrm{H} / \mathrm{a}$ & 0.20 & 0.12 & 0.83 & 0.11 & $\mathrm{H} / \mathrm{a}$ & 0.12 & 0.073 & $\mathrm{H} / \mathrm{a}$ & 0.15 & 0.10 \\
\hline $\mathbf{K}_{2} \mathbf{O}$ & $\mathrm{H} / \mathrm{a}$ & 0.10 & 0.07 & 1.29 & 0.16 & 0.61 & 0.35 & 0.35 & $\mathrm{H} / \mathrm{a}$ & $\mathrm{H} / \mathrm{a}$ & 0.15 \\
\hline $\mathbf{P}_{2} \mathbf{O}_{5}$ & 0.40 & 0.08 & 0.01 & 0.17 & 0.07 & 0.14 & 2.59 & 0.04 & 0.06 & 0.58 & 0.01 \\
\hline $\mathrm{CO}_{2}$ & 1.72 & 0.11 & 0.39 & 1.07 & 4.14 & 3.44 & 1.06 & 0.22 & 0.21 & 0.25 & 36.67 \\
\hline $\mathrm{H}_{2} \mathrm{O}^{ \pm}$ & 1.86 & 0.30 & 0.41 & 0.34 & 0.42 & 1.34 & 12.08 & 0.63 & 0.74 & 1.29 & 0.37 \\
\hline $\mathbf{S}$ & 0.02 & 4.16 & 3.89 & 0.25 & 1.08 & 1.63 & 0.13 & 0.70 & 0.01 & $\mathrm{H} / \mathrm{a}$ & 0.21 \\
\hline $\mathrm{BaO}$ & $\mathrm{H} / \mathrm{a}$ & $\mathrm{H} / \mathrm{a}$ & $\mathrm{H} / \mathrm{a}$ & $\mathrm{H} / \mathrm{a}$ & 0.38 & 0.12 & 0.14 & 3.46 & $\mathrm{H} / \mathrm{a}$ & $\mathrm{H} / \mathrm{a}$ & $\mathrm{H} / \mathrm{a}$ \\
\hline
\end{tabular}

\section{Рентгенофазовый анализ}

Для стандартных образцов ОСО 181-89, ОСО 183-89, ОСО 184-89, ЗД-1, 5403-90 и СО-20 фазовый состав приведен в паспортах, для остальных образцов (4б, Р31, Р7г, Р9б и НФС-28) оценили минеральный состав с помощью рентгеновского порошкового дифрактометра D8 Advance (Bruker), оснащенным сцинтилляционным детектором и зеркалом Гёбеля. Источником излучения служит рентгеновская трубка с медным анодом, напряжение на котором составляло 40 кВ, ток - 40 мА. Сканирование проводили с шагом $0.02^{\circ}$ и скоростью 1 с/шаг. Образцы готовили набивкой и выравниваем порошка в специальной кювете, общее время измерения одной пробы составляло около 60 мин. На рис. 1 приведены дифрактограммы стандартных образцов 4 и Р7г. Высокий фон, вызванный флуоресценцией железа, возбужденной излучением рентгеновской трубки $(\mathrm{CuK \alpha})$, позволил провести лишь качественный анализ образцов, то есть идентифицировать основные фазы железа (гематит, магнетит, гетит) и некоторые другие минералы с высоким содержанием. Исследуемые руды сформировались в различных геологических обстановках и отличаются по минеральному составу: в одних преобладают силикаты, в других - карбонаты, в содержаниях которых также отмечены значительные вариации.

\section{Кластерный анализ}

Первичная оценка и разбитие образцов на группы проводили при помощи кластер-анализа [14]. Его основное назначение - разделение множества исследуемых объектов и признаков на однородные по выбранным параметрам группы. Достоинство кластерного анализа в том, что 


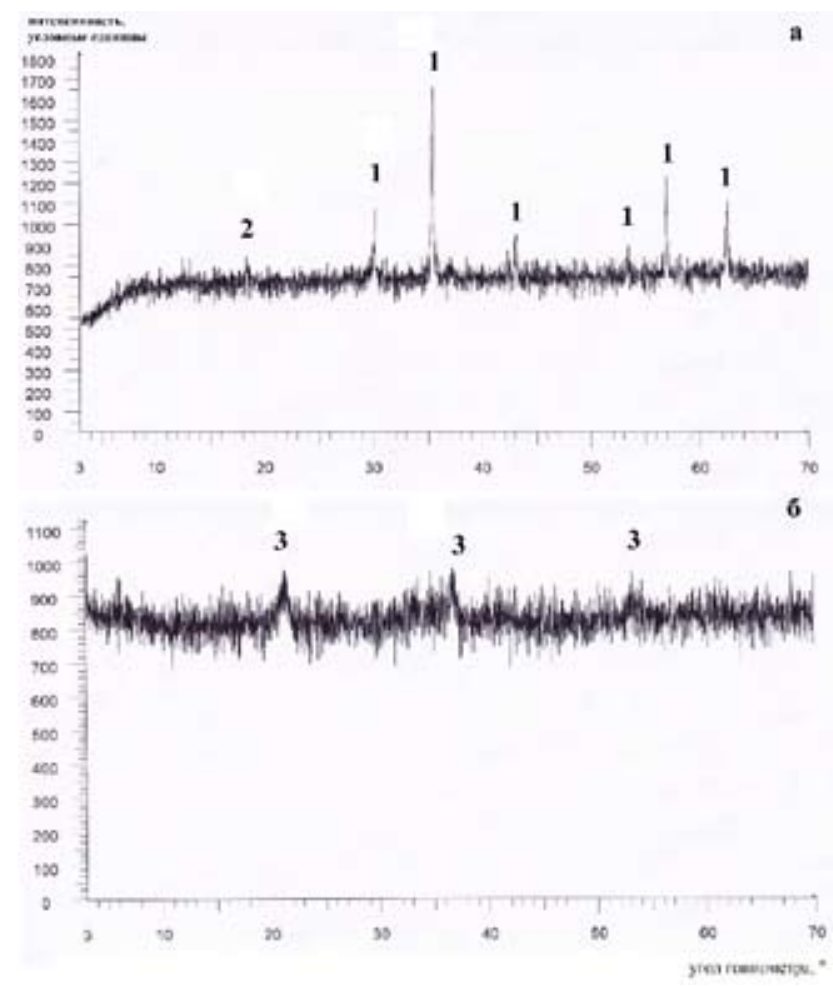

Обозначения: 1 - магнетит, 2 - клинохлор, 3 - гетит.

Рис. 1. Дифрактограммы стандартных образцов железных руды 4б (а) и Р7г (б)

Fig. 1. Diffractograms of iron ore certified reference materials $4 b$ (a) and R7g (б)

он дает возможность производить классификацию объектов по ряду признаков, для которых автоматически определяют степень корреляции, что позволяет установить причины выделения кластеров. Алгоритм и особенности интерпретации иерархических дендрограмм Q-анализа описаны в работах $[15,16]$. Среди исследуемых проб железных руд были выделены группы, отличные по химическому составу (рис. 2).

К первой группе относятся ОСО 184-89, 5403-90, ОСО 181-89 и 4б, отличающиеся наибольшим содержанием железа. Выделение второй группы (Р39, СО-20, ОСО 183-89) связано с высоким содержанием $\mathrm{CO}_{2}$, что объясняется присутствием карбонатов. Для третьей группы (ЗД-1, Р7г, НФС-28) характерны высокие содержания $\mathrm{Fe}_{2} \mathrm{O}_{3}$ и $\mathrm{SiO}_{2}$ (до 17.5 \%). Стандартный образец Р9б был выделен в отдельный кластер по причине большого содержания $\mathrm{CO}_{2}$ и $\mathrm{FeO}$. Такое разбиение на подгруппы позволило при моделировании больше внимания уделить акцессорным минералам различных групп. С целью адекватного описания фазового состава в модель включили дополнительно силикаты и карбонаты.

\section{Физико-химическое моделирование минерального состава на основе данных о содержании элементов}

Метод физико-химического моделирования, основанный на определении глобального минимума термодинамического потенциала (энергии Гиббса) моделируемой системы на

$$
-69-
$$




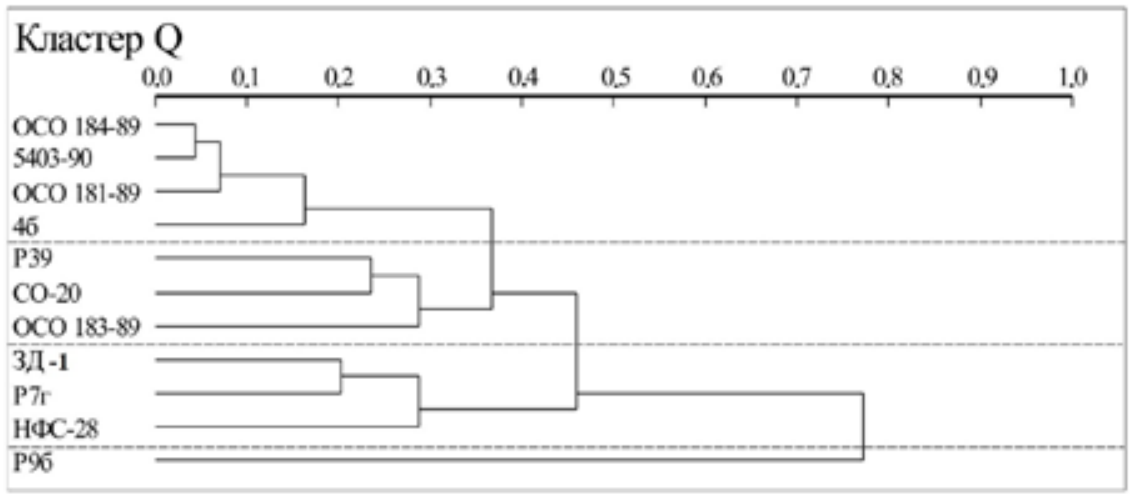

Рис. 2. Кластер-анализ по химическому составу стандартных образцов железных руд

Fig. 2. Cluster analysis by chemical composition of certified reference materials of iron ores

множестве ограничений, задаваемых системой уравнения баланса масс, неотрицательностью мольных количеств зависимых компонентов $[13,17]$, был реализован в программном комплексе «Селектор» [18]. Компьютерная модель вычисляет минеральный парагенезис в зависимости от химического состава породы и других наложенных условий, определяющих термодинамическое равновесие системы, при этом выдерживается разделение на независимые и зависимые компоненты. Приведенный изобарно-изотермический потенциал системы

$$
G(x)=G / R T,
$$

где $\mathrm{G}$ - свободная энергия Гиббса системы; $T$ - температура, $\mathrm{K} ; ~ R$ - универсальная газовая постоянная, может быть представлен как

$$
G(\mathrm{x})=\sum\left(\frac{\mathrm{g}_{j}}{R T}+\ln \gamma_{j}\right) x_{j}+\sum x_{j} \ln \frac{x_{j}}{X_{\alpha}}
$$

где $x_{j}$ - число молей зависимого компонента $j ; X_{\alpha}=\sum x_{j}$ - сумма молей зависимых компонентов в фазе $\alpha ; \mathrm{g}_{j}-$ нормализованная эмпирическая функция свободной энергии зависимого компонента $j ; j$ - число зависимых компонентов; $\gamma_{j}$ - коэффициент активности компонента $j$. В решении рассматривается гетерогенная мультисистема из зависимых компонентов, которая включает конденсированные однокомпонентные фазы и фазы твердых растворов, смоделированные на основе независимых компонентов (элементов): $\mathrm{Si}, \mathrm{Al}, \mathrm{C}, \mathrm{Ca}, \mathrm{Fe}, \mathrm{K}, \mathrm{Mg}$, $\mathrm{Na}, \mathrm{S}, \mathrm{H}, \mathrm{O}, \mathrm{Ba}, \mathrm{Mn}$, Ti и P. В модели предполагалось, что формирование фаз происходило при нормальных условиях. В табл. 2 приведены включенные в модель зависимые компоненты, а также значения изменения свободной энергии Гиббса $\left(\Delta G^{0}\right)$ с указанием источника данных, используемые для расчета суммарной энергии системы в соответствии с мольными долями компонентов.

В модели также рассчитывают обобщенные стехиометрические формулы минералов с переменным составом (полевые шпаты, карбонаты, слоистые алюмосиликаты), что позволяет повысить точность расчета [24-27]. 
Таблица 2. Список вероятных минеральных фаз при физико-химическом моделировании фазового состава железных руд

Table 2. List of possible mineral phases for physic-chemical modeling of mineral composition of iron ores

\begin{tabular}{|c|c|c|c|c|}
\hline & Минерал & Формула & $\Delta G^{0}$, кал/моль & Источник \\
\hline 1 & 2 & 3 & 4 & 5 \\
\hline \multirow{6}{*}{ Минералы железа } & Пирит & $\mathrm{FeS}_{2}$ & -38293 & [19] \\
\hline & Пирротин & $\mathrm{FeS}$ & -24084 & {$[19]$} \\
\hline & Гематит & $\mathrm{Fe}_{2} \mathrm{O}_{3}$ & -178155 & {$[19]$} \\
\hline & Магнетит & $\mathrm{Fe}_{3} \mathrm{O}_{4}$ & -242574 & {$[19]$} \\
\hline & Сидерит & $\mathrm{FeCO}_{3}$ & -162414 & {$[19]$} \\
\hline & Гетит & $\begin{array}{l}\mathrm{Fe}(\mathrm{OH})_{3} \\
\mathrm{FeO}(\mathrm{OH})\end{array}$ & $\begin{array}{l}-166491 \\
-116829\end{array}$ & $\begin{array}{l}{[20]} \\
{[21]}\end{array}$ \\
\hline \multirow{10}{*}{$\begin{array}{l}\text { Породо- } \\
\text { образующие } \\
\text { силикаты }\end{array}$} & Кварц & $\mathrm{SiO}_{2}$ & -204646 & [19] \\
\hline & Полевые шпаты & $\begin{array}{l}\mathrm{NaAlSi}_{3} \mathrm{O}_{8} \\
\mathrm{CaAl}_{2} \mathrm{Si}_{2} \mathrm{O}_{8} \\
\mathrm{KAlSi}_{3} \mathrm{O}_{8} \\
\end{array}$ & $\begin{array}{l}-885765 \\
-957261 \\
-892826 \\
\end{array}$ & {$[21]$} \\
\hline & $\begin{array}{l}\text { Хлориты } \\
\text { (8 миналов) }\end{array}$ & $\begin{array}{l}\mathrm{Al}_{4} \mathrm{Si}_{4} \mathrm{O}_{10}(\mathrm{OH})_{8} \\
\mathrm{Fe}_{3} \mathrm{Si}_{2} \mathrm{O}_{5}(\mathrm{OH})_{4} \\
\mathrm{Fe}_{4} \mathrm{Al}_{4} \mathrm{Si}_{2} \mathrm{O}_{10}(\mathrm{OH})_{8} \\
\mathrm{Fe}_{5} \mathrm{Al}_{2} \mathrm{Si}_{3} \mathrm{O}_{10}(\mathrm{OH})_{8} \\
\mathrm{Fe}_{6} \mathrm{Al}_{2} \mathrm{Si}_{3} \mathrm{O}_{10}(\mathrm{OH})_{7} \\
\mathrm{Mg}_{4} \mathrm{Al}_{4} \mathrm{Si}_{2} \mathrm{O}_{10}(\mathrm{OH})_{8} \\
\mathrm{Mg}_{5} \mathrm{Al}_{2} \mathrm{Si}_{3} \mathrm{O}_{10}(\mathrm{OH})_{8} \\
\mathrm{Mg}_{6} \mathrm{Si}_{4} \mathrm{O}_{10}(\mathrm{OH})_{8} \\
\end{array}$ & $\begin{array}{l}-1820990 \\
-716084 \\
-1663620 \\
-1548470 \\
-1556260 \\
-1993640 \\
-1959450 \\
-1924370 \\
\end{array}$ & {$[21]$} \\
\hline & $\begin{array}{l}\text { Гидрослюды } \\
\text { (6 миналов) }\end{array}$ & \begin{tabular}{|l|}
$\mathrm{KAl}_{3} \mathrm{Si}_{3} \mathrm{O}_{10}(\mathrm{OH})_{2}$ \\
$\mathrm{KFe}_{2} \mathrm{AlSi}_{3} \mathrm{O}_{10}(\mathrm{OH})_{2}$ \\
$\mathrm{KFeAlSi}_{4} \mathrm{O}_{10}(\mathrm{OH})_{2}$ \\
$\mathrm{KMgAlSi}_{4} \mathrm{O}_{10}(\mathrm{OH})_{2}$ \\
$\mathrm{NaAl}_{3} \mathrm{Si}_{3} \mathrm{O}_{10}(\mathrm{OH})_{2}$ \\
\end{tabular} & $\begin{array}{l}-1338280 \\
-1127690 \\
-1221130 \\
-1303920 \\
-1329470 \\
\end{array}$ & {$[21]$} \\
\hline & Каолинит & $\mathrm{Al}_{4} \mathrm{Si}_{4} \mathrm{O}_{10}(\mathrm{OH})_{8}$ & -1820990 & [21] \\
\hline & $\begin{array}{l}\text { Пироксены } \\
\text { (2 минала) } \\
\end{array}$ & $\begin{array}{l}\mathrm{CaMgSi}_{2} \mathrm{O}_{6} \\
\mathrm{CaFeSi}_{2} \mathrm{O}_{6} \\
\end{array}$ & $\begin{array}{l}-723599 \\
-639484 \\
\end{array}$ & [21] \\
\hline & $\begin{array}{l}\text { Амфиболы } \\
\text { (5 миналов) }\end{array}$ & $\begin{array}{l}\mathrm{Na}_{2} \mathrm{FeAl}_{6} \mathrm{Si}_{6} \mathrm{O}_{22}(\mathrm{OH})_{2} \\
\mathrm{Na}_{2} \mathrm{Fe}_{4} \mathrm{MgAl}_{2} \mathrm{Si}_{6} \mathrm{O}_{22}(\mathrm{OH})_{2} \\
\mathrm{~K}_{2} \mathrm{CaMg}_{5} \mathrm{Si}_{8} \mathrm{O}_{22}(\mathrm{OH})_{2} \\
\mathrm{Ca}_{2} \mathrm{Fe}_{5} \mathrm{Si}_{8} \mathrm{O}_{22}(\mathrm{OH})_{2} \\
\mathrm{Ca}_{2} \mathrm{Mg}_{5} \mathrm{Si}_{8} \mathrm{O}_{22}(\mathrm{OH})_{2} \\
\end{array}$ & $\begin{array}{l}-2652070 \\
-2332770 \\
-2780500 \\
-2352710 \\
-2736320 \\
\end{array}$ & [21] \\
\hline & $\begin{array}{l}\text { Гранаты } \\
\text { (4 минала) }\end{array}$ & $\begin{array}{l}\mathrm{Fe}_{3} \mathrm{Al}_{2} \mathrm{Si}_{3} \mathrm{O}_{12} \\
\mathrm{Ca}_{3} \mathrm{Fe}_{2} \mathrm{Si}_{3} \mathrm{O}_{12} \\
\mathrm{Ca}_{3} \mathrm{Al}_{2} \mathrm{Si}_{3} \mathrm{O}_{12} \\
\mathrm{Mg}_{3} \mathrm{Al}_{2} \mathrm{Si}_{3} \mathrm{O}_{12} \\
\end{array}$ & $\begin{array}{l}-1180090 \\
-1294020 \\
-1499960 \\
-1420340 \\
\end{array}$ & {$[21]$} \\
\hline & Серпентин & $\mathrm{Mg}_{6} \mathrm{Si}_{4} \mathrm{O}_{10}(\mathrm{OH})_{8}$ & -1929820 & {$[21]$} \\
\hline & Сфен & $\mathrm{CaTiSiO}_{5}$ & -587349 & [19] \\
\hline \multirow{4}{*}{ Карбонаты } & Кальцит & $\mathrm{CaCO}_{3}$ & -269880 & [19] \\
\hline & Магнезит & $\mathrm{MgCO}_{3}$ & -245658 & [19] \\
\hline & Доломит & $\mathrm{CaMg}\left(\mathrm{CO}_{3}\right)_{2}$ & -517760 & [19] \\
\hline & Родохрозит & $\mathrm{MnCO}_{3}$ & -195045 & [19] \\
\hline
\end{tabular}


Продолжение табл. 1

Continuation Table. 1

\begin{tabular}{|l|l|l|c|c|}
\hline \multicolumn{1}{|c|}{1} & \multicolumn{1}{|c|}{2} & \multicolumn{1}{|c|}{3} & \multicolumn{1}{c|}{5} \\
\hline \multirow{5}{*}{$\begin{array}{l}\text { Оксиды и } \\
\text { гидрооксиды }\end{array}$} & \multirow{2}{*}{ Псиломелан } & $\mathrm{MnO}_{2}$ & -109002 & {$[21]$} \\
\cline { 2 - 5 } & $\mathrm{MnO}$ & -86735 & {$[21]$} \\
\hline \multirow{4}{*}{ Сульфаты } & Ильменит & $\mathrm{FeTiO}_{3}$ & -276171 & {$[22]$} \\
\cline { 2 - 5 } & Рутил & $\mathrm{TiO}_{2}$ & -212323 & {$[21]$} \\
\hline \multirow{2}{*}{ Фосфаты } & Гипс & $\mathrm{CaSO}_{4}\left(\mathrm{H}_{2} \mathrm{O}\right)_{2}$ & -429598 & {$[21]$} \\
\cline { 2 - 5 } & Ангидрит & $\mathrm{CaSO}_{4}$ & -315925 & {$[19]$} \\
\cline { 2 - 5 } & Барит & $\mathrm{BaSO}_{4}$ & -325563 & {$[19]$} \\
\hline
\end{tabular}

\section{Результаты и обсуждение}

Результаты количественного определения фазового состава стандартных образцов железных руд были сопоставлены с данными качественного рентгенофазового анализа для стандартных образцов железных руд, фазовый состав которых не приведен в паспорте (табл. 3). Минералы приведены в порядке уменьшения содержания.

Оба метода идентифицируют основной рудный компонент, однако метод физикохимического моделирования позволяет дополнительно получить сведения о минеральном составе вмещающей породы, в то время как метод рентгеновской порошковой дифракции не об-

Таблица 3. Сопоставление результатов определения качественного фазового состава стандартных образцов железных руд методами физико-химического моделирования и рентгеновской порошковой дифракции

Table 3. Comparison of results of qualitative mineral composition of certified reference materials of iron ores determined by physic-chemical modeling and X-ray powder diffraction

\begin{tabular}{|c|c|c|}
\hline \multirow[b]{2}{*}{$\begin{array}{l}\text { Стандартный } \\
\text { образец }\end{array}$} & \multicolumn{2}{|r|}{ Метод } \\
\hline & $\begin{array}{c}\text { Рентгеновская } \\
\text { порошковая } \\
\text { дифракция }\end{array}$ & Физико-химическое моделирование \\
\hline 46 & $\begin{array}{c}\text { Магнетит } \\
\text { Хлориты } \\
\text { (клинохлор) }\end{array}$ & $\begin{array}{l}\text { Магнетит (62.9 \%), Хлориты (13.6 \%), Гранаты (9.0 \%), Кварц (4.5 \%), } \\
\text { Амфиболы (3.5 \%), Кальцит (3.2 \%), Сфен (0.8 \%), Родохрозит (0.8 \%) }\end{array}$ \\
\hline Р9б & $\begin{array}{l}\text { Сидерит } \\
\text { Анкерит }\end{array}$ & $\begin{array}{l}\text { Сидерит (62.5 \%), Магнезит (19.6 \%), Кальцит (4.3\%), } \\
\text { Магнетит (4.1\%), Амфиболы (2.9\%), Хлориты (2.4\%), } \\
\text { Родохрозит (2.2\%) }\end{array}$ \\
\hline НФС-28 & Гематит & Гематит (85.3 \%), Гетит (12.3 \%), Сидерит (0.7 \%), Гидрослюды (0.7 \%) \\
\hline P39 & $\begin{array}{c}\text { Магнетит } \\
\text { Кварц } \\
\text { Гидромусковит } \\
\text { Полевые шпаты }\end{array}$ & $\begin{array}{l}\text { Кварц (38.8 \%), Магнетит (37.8 \%), Амфиболы (8.3 \%), } \\
\text { Полевые шпаты (5.7 \%), Гидрослюды (3.5 \%), Кальцит (1.4 \%), } \\
\text { Сидерит (1.1 \%) }\end{array}$ \\
\hline $\mathrm{P} 7 \Gamma$ & Гетит & $\begin{array}{l}\text { Гетит (57.0 \%), Хлориты (10.7 \%), Кварц (7.0 \%), Гематит }(8.0 \text { \%), } \\
\text { Вивианит (5.4 \%), Гидрослюды (3.1 \%), Родохрозит (2.5 \%), } \\
\text { Гидроксиапатит (2.5 \%), Псиломелан (0.8 \%), Полевые шпаты (0.8 \%) }\end{array}$ \\
\hline
\end{tabular}


наруживает фазы с содержанием менее $5 \%$. Анкерит $\mathrm{CaFe}^{2+}\left(\mathrm{CO}_{3}\right)_{2}$ представляет собой карбонат группы доломита, образующий изоморфные ряды с доломитом $\left(\mathrm{CaMg}\left(\mathrm{CO}_{3}\right)_{2}\right)$ и кутногоритом $\left(\mathrm{CaMn}^{2+}\left(\mathrm{CO}_{3}\right)_{2}\right)$, в модели он описывается твердым раствором сидерит-магнезит-кальцит в различных соотношениях. Для стандартных образцов было проведено сопоставление фазовых составов, полученных физико-химическим моделированием («Расчет»), с данными сертификата стандартного образца «Паспорт» (табл. 4).

В образце ОСО 183-89 в незначительных количествах присутствуют: полевой шпат - альбит $\left(\mathrm{NaAlSi}_{3} \mathrm{O}_{8}\right)(0.59 \%)$, вивианит (0.15\%), рутил и родохрозит (менее $\left.0.1 \%\right)$. Расчетная кристаллохимическая формула хлорита: $\mathrm{Fe}_{0.21} \mathrm{Mg}_{0.03} \mathrm{Al}_{3.55}\left[\mathrm{Al}_{0.15} \mathrm{Si}_{3.85}\right] \mathrm{O}_{10}(\mathrm{OH})_{8}$; гидромусковита $-\mathrm{K}_{0.98}$ $\mathrm{Na}_{0.02} \mathrm{Mg}_{0.23} \mathrm{Fe}_{0.84} \mathrm{Al}_{0.94}\left[\mathrm{Al}_{0.20} \mathrm{Si}_{3.80}\right] \mathrm{O}_{10}\left(\mathrm{H}_{2} \mathrm{O}\right)$.

В образце ОСО 184-89 также обнаружены амфиболы (0.52 \%), рутил (0.05\%), гидроксиапатит (0.16 \%). Полевой шпат представлен альбитом. Хлорит имеет формулу $\mathrm{Fe}_{0.04} \mathrm{Mg}_{1.15} \mathrm{Al}_{3.23}$ $\left[\mathrm{Al}_{0.26} \mathrm{Si}_{3.74}\right] \mathrm{O}_{10}(\mathrm{OH})_{8}$, гидромусковит - $\mathrm{K}_{1.00} \mathrm{Mg}_{0.07} \mathrm{Fe}_{0.14} \mathrm{Al}_{1.79}\left[\mathrm{Al}_{0.90} \mathrm{Si}_{3.10}\right] \mathrm{O}_{10}\left(\mathrm{H}_{2} \mathrm{O}\right)$.

В образце ОСО 181-89, по данным моделирования, титан вошел в состав сфена (0.17 \%), присутствуют родохрозит (0.25\%), гидроксиапатит (0.19\%). В твердом растворе полевого шпата находится только альбит. Гранат представлен кальциевыми разностями со сводной формулой $\mathrm{Ca}_{3} \mathrm{Al}_{1.3} \mathrm{Fe}^{+3}{ }_{0.7}\left[\mathrm{SiO}_{4}\right]_{3}$. В амфиболах по составу преобладают кальций-железистые и кальций-магниевые миналы. В рассчитанный состав хлорита входит железо и магний $\mathrm{Fe}_{3.50} \mathrm{Mg}_{1.08} \mathrm{Al}_{0.63}\left[\mathrm{Al}_{1.41} \mathrm{Si}_{2.59}\right] \mathrm{O}_{10}(\mathrm{OH})_{8}$.

В образце СО-20 присутствуют минеральные фазы сфена (1.19 \%), барита (0.18 \%), гидроксиапатита (0.33 \%). Полевые шпаты по составу - калиевые. Гранаты андрадитового ряда, со сводной формулой $\mathrm{Ca}_{3.00} \mathrm{Al}_{1.18} \mathrm{Fe}^{+3}{ }_{0.82}\left[\mathrm{SiO}_{4}\right]_{3}$. Хлорит преимущественно магниевый: $\mathrm{Mg}_{4.44} \mathrm{Al}_{1.54}\left[\mathrm{Al}_{1.48} \mathrm{Si}_{2.52}\right] \mathrm{O}_{10}(\mathrm{OH})_{8}$.

В образце ЗД-1 методом моделирования установлено наличие сидерита $(0.46 \%)$ и вивианита $(0.21 \%)$, а также родохрозита и пирита $(<0.1 \%)$. Минерал мартит, наличие которого указано в эталоне, представляет собой псевдоморфозу гематита по магнетиту. Такие структурные преобразования не могут быть установлены методом физико-химического моделирования, в расчетах были объединены фазы гематит и мартит, имеющие одинаковую химическую формулу $\left(\mathrm{Fe}_{2} \mathrm{O}_{3}\right)$, но различающиеся структурно.

В образце 5403-90 карбонаты представлены кальцитом (0.6 \%) и родохрозитом (0.3\%), обнаружены гидроксиапатит и гетит (менее $0.1 \%$ ). Сидерит и гранаты не обнаружены. Полевой шпат по составу соответствует альбиту. Сводная стехиометрическая формула хлоритов $-\mathrm{Fe}_{0.21} \mathrm{Mg}_{2.26} \mathrm{Al}_{2.22}\left[\mathrm{Al}_{0.59} \mathrm{Si}_{3.41}\right] \mathrm{O}_{10}(\mathrm{OH})_{8}$. Различие в соотношении силикатов обусловлено тем, что модель ориентирована на определение рудных минералов железа, в то время как твердые растворы гранатов, амфиболов, полевых шпатов, подобранные на основе обобщенных химикоаналитических данных, недостаточно обширны.

\section{Заключение}

Железные руды представляют собой сложные минеральные системы, содержащие помимо минералов железа также силикаты, карбонаты и оксиды других элементов. Методы рентгеновской дифракции и электронно-зондового микроанализа часто позволяют только качественно оценить минеральный (фазовый) состав руд. Метод физико-химического моделирования, опи- 
Таблица 4. Сопоставление результатов физико-химического моделирования минерального состава стандартных образцов железных руд ОСО 183-89, ОСО 184-89, ОСО 181-89, СО-20, 5403-90 и ЗД-1 со значениями, приведенными в паспорте

Table 4. Comparison of results of physic-chemical modeling of mineral composition and values in certificate for certified reference materials of iron ores OSO 183-89, OSO 184-89, OSO 181-89, SO-20, 5403-90 and ZD-1

\begin{tabular}{|c|c|c|c|c|c|c|c|c|c|c|c|c|}
\hline OCO 183-89 & 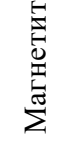 & 志 & 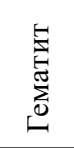 & $\begin{array}{l}\bar{\Xi} \\
\overline{0} \\
\overline{0} \\
\text { J }\end{array}$ & \multicolumn{2}{|c|}{ 莺 } & \multicolumn{2}{|c|}{ 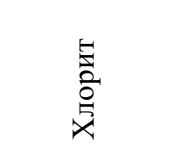 } & $\begin{array}{l}\text { 芯 } \\
\text { 鱼 }\end{array}$ & \multicolumn{2}{|c|}{ 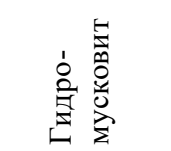 } & 窝 \\
\hline Паспорт, \% & 0.5 & 0.02 & 48.1 & 1.1 & \multicolumn{2}{|c|}{0.8} & \multicolumn{2}{|c|}{0.2} & 38.8 & \multicolumn{2}{|c|}{5.2} & 5.1 \\
\hline Расчет, \% & 1.5 & 0.1 & 49.6 & 0.6 & \multicolumn{2}{|c|}{0.5} & \multicolumn{2}{|c|}{3.1} & 39.9 & \multicolumn{2}{|c|}{3.3} & 5.1 \\
\hline OCO 184-89 & 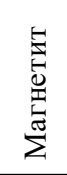 & $\begin{array}{l}\text { 总 } \\
\text { 恶 }\end{array}$ & 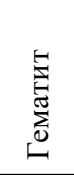 & $\begin{array}{l}E \\
\frac{1}{2} \\
\overline{0} \\
\text { 已 }\end{array}$ & $\stackrel{\Xi}{\stackrel{\Xi}{\leftrightarrows}}$ & 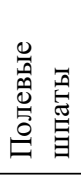 & 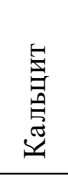 & $\begin{array}{l}5 \\
\stackrel{5}{2} \\
\stackrel{2}{5} \\
x\end{array}$ & 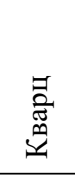 & 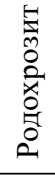 & 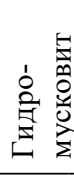 & 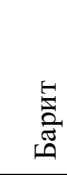 \\
\hline Паспорт, \% & 49.8 & 1.9 & 25.0 & 7.6 & 0.3 & 1.8 & 2.2 & 3.5 & 5.8 & 0.8 & 0.5 & 0.6 \\
\hline Расчет, \% & 47.8 & 1.8 & 29.6 & 7.4 & $<0.1$ & 0.9 & 2.4 & 1.4 & 6.0 & 0.8 & 1.0 & 0.6 \\
\hline OCO 181-89 & 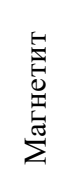 & 志 & 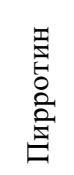 & 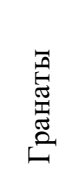 & \multicolumn{2}{|c|}{ 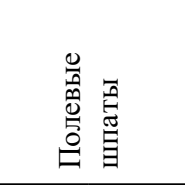 } & 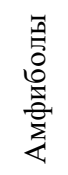 & $\begin{array}{l}5 \\
\stackrel{5}{2} \\
\stackrel{2}{5} \\
\dot{x}\end{array}$ & \multicolumn{2}{|c|}{ 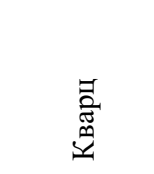 } & \multicolumn{2}{|c|}{ 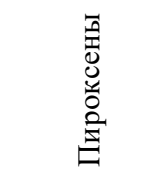 } \\
\hline Паспорт, \% & 77.5 & 0.8 & 9.4 & 1.0 & \multicolumn{2}{|c|}{2.4} & 4.6 & $<0.1$ & \multicolumn{2}{|c|}{0.6} & \multicolumn{2}{|c|}{2.0} \\
\hline Расчет, \% & 77.4 & 1.0 & 8.1 & 3.9 & \multicolumn{2}{|c|}{1.7} & 5.5 & 1.8 & \multicolumn{2}{|c|}{$<0.1$} & \multicolumn{2}{|c|}{$<0.1$} \\
\hline $\mathrm{CO}-20$ & 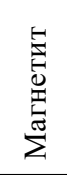 & 志 & $\begin{array}{l}5 \\
0 \\
0 \\
0 \\
0 \\
0\end{array}$ & 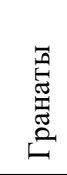 & \multicolumn{2}{|c|}{ 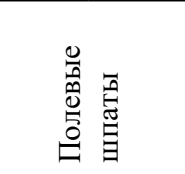 } & 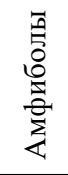 & 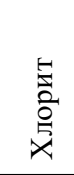 & & & \multicolumn{2}{|c|}{ 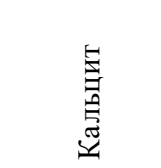 } \\
\hline Паспорт, \% & 34.4 & 3.2 & 15.1 & 24.7 & \multicolumn{2}{|c|}{7.6} & 3.3 & 3.1 & & & \multicolumn{2}{|c|}{7.2} \\
\hline Расчет, \% & 34.6 & 3.2 & 7.3 & 23.0 & \multicolumn{2}{|c|}{3.7} & $<0.1$ & 6.2 & \multicolumn{2}{|c|}{11.4} & \multicolumn{2}{|c|}{8.0} \\
\hline 5403-90 & 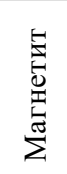 & 怘 & 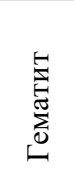 & 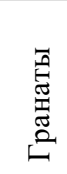 & \multicolumn{2}{|c|}{ 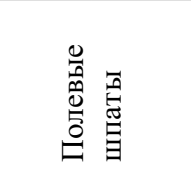 } & 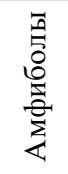 & 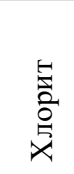 & \multicolumn{2}{|c|}{ 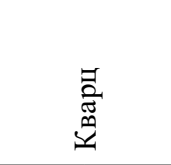 } & 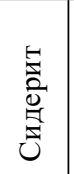 & 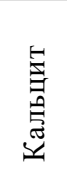 \\
\hline Паспорт, \% & 79.1 & 6.6 & 1.0 & 1.1 & \multicolumn{2}{|c|}{1.0} & 2.7 & 1.4 & \multicolumn{2}{|c|}{3.8} & 1.1 & 0.1 \\
\hline Расчет, \% & 76.7 & 6.0 & 5.7 & - & \multicolumn{2}{|c|}{0.3} & 2.3 & 1.8 & \multicolumn{2}{|c|}{5.1} & - & 0.6 \\
\hline ЗД-1 & 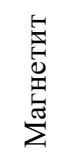 & $\begin{array}{l}E \\
\text { 吾 } \\
\vdots \\
\vdots \\
\vdots\end{array}$ & 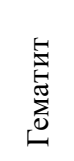 & $\begin{array}{l}\frac{5}{5} \\
\stackrel{5}{2} \\
\sum_{2}\end{array}$ & \multicolumn{3}{|c|}{ 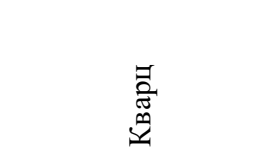 } & \multicolumn{5}{|c|}{ 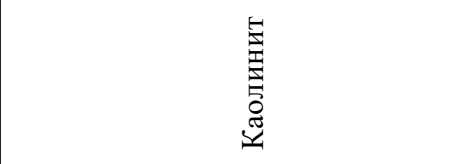 } \\
\hline Паспорт, \% & 5.2 & 3.0 & 34.4 & 39.4 & \multicolumn{3}{|c|}{15.9} & & & 2.1 & & \\
\hline Расчет, \% & 4.9 & 3.4 & & & & 16.2 & & & & 2.9 & & \\
\hline
\end{tabular}


раясь на данные химического состава, дает возможность не только предсказать основные минеральные фазы, но и установить их количество. Расчетные содержания силикатных минералов в ряде случаев расходятся с аналитически определенными, поскольку моделирование нацелено на оценку железорудных минералов и модели твердых растворов алюмосиликатов идеализированы. Определение минерального состава методом физико-химического моделирования позволяет установить минеральные фазы, содержащиеся в пробе в количестве от десятых долей процента (что затруднительно другими методами), однако не всегда возможно установить полиморфные модификации ряда минералов. Сложные минералы, образующие изоморфные ряды, могут быть рассчитаны как смесь более простых минералов. Точность расчета может быть повышена использованием дополнительных данных о минеральном составе, позволяющих расширить список миналов в твердом растворе и приблизить его к обнаруженным фазам.

\section{Благодарности / Acknowledgements}

Исследования выполнены с использованием оборудования Центра коллективного пользования «Изотопно-геохимических исследований» ИГХ СО РАН при финансовой поддержке Российского Фонда Фундаментальных исследований (проект № 18-33-20104).

The research was performed using equipment of the Siberian Branch of the Russian Academy of Sciences Joint use Isotope-geochemical Research Center and with financial support of the Russian Foundation for Basic Researches funding (grant No. 18-33-20104).

\section{Список литературы / References}

1. Смирнов В.И. Геология полезных ископаемых. М.: Недра, 1976. 688 с. [Smirnov V.I. Geology of mineral resources. Moscow: Nedra, 1976. 688 p. (In Russ.)]

2. Ляликов Ю.С., Сакунов В.И., Ткаченко Н.С. Анализ железных и марганцевых руд. М.: Металлургиздат, 1954. 273 с. [Lialikov Iu.S., Sakunov V.I., Tkachenko N.S. Analysis of iron and manganese ores. Moscow: Metallurgizdat, 1954. 273 p. (In Russ.)]

3. Пономарев А.Н. Методы химического анализа силикатных и карбонатных горных пород. М.: Изд-во АНССCР, 1961. 414 с. [Ponomarev A.N. Chemical analysis methods for silicate and carbonate rocks. Moscow: USSRAcademy of Sciences Press, 1961. 414 p. (In Russ.)]

4. Alov N.V., Volkov A.I., Usherov A.I., Ishmet'ev E.N., Usherova E.V. Continuous X-ray Fluorescence Analysis of IronOre Mixtures in the Production of Agglomerate. Journal of Analytical Chemistry 2010. Vol. 65 (2), P. 169-173.

5. Volkov N.V., Alov I.V. Method for Improving the Accuracy of Continuous X-ray Fluorescence Analysis of IronOre Mixtures. Journal of Analytical Chemistry 2010. Vol. 65 (2), P. 732-738.

6. Чубаров В.М., Финкельштейн А.Л., Амиржанов А.А. Определение отношения $\mathrm{FeO} / \mathrm{Fe}_{2} \mathrm{O}_{3}{ }^{\text {tot }}$ в железных рудах по эмиссионным линиям К-серии рентгеновского флуоресцентного спектра. Аналитика и контроль 2009. T. 13(3), C. 141-146. [Chubarov V.M., Finkel'shtein A.L., Amirzhanov A.A. $\mathrm{X}$-ray fluorescence determination of $\mathrm{FeO} / \mathrm{Fe}_{2} \mathrm{O}_{3}$ tot ratio in iron ores using $\mathrm{K}$-series emission lines of X-ray fluorescence spectrum. Analysis and Control 2009. Vol. 13(3), P. 141-146. (In Russ.)]

7. Shaltout A.A., Gomma M.M., Ali-Bik M.W. Utilization of standardless analysis algorithms using WDXRF and XRD for Egyptian iron ore identification. X-ray spectrometry 2012. Vol. 41, P. 355-362. 
8. Бахтиаров А.В., Савельев С.К. Рентгенофлуоресцентный анализ минерального сырья. СПб.: Изд-во С.-Петербург. ун-та, 2014. 132 с. [Bakhtiarov A.V., Savel'ev S.K. X-ray fluorescence analysis of mineral raw. St. Petersburg: St. PetersburgUniversity, 2014. 132 p. (In Russ.)]

9. Jenkins R., Snyder R.L. Introduction to X-ray Powder Diffractometry. Willey, New-York, 1996. $432 \mathrm{p}$.

10. Reed S.J.B. Electron Microprobe Analysis and Scanning Electron Microscopy in Geology. Cambridge University Press, New Yore, Melbourne. 2009. 206 p.

11. Madsen I.C., Scarlett N.V.Y., Cranswick L.M.D., Lwin T. Outcomes of the International Union of Crystallography Commission on Powder Diffraction Round Robin on Quantitative Phase Analysis. Journal of Applied Crystallography 2001. Vol. 34, P. 409-426.

12. Ожогина Е.Г., Лебедева М.И., Горбатова Е.А. Межлабораторные сравнительные испытания в минералогических работах. Стандартные образиы 2017. Т. 13(2), С. 37-47. [Ozhogina E.G., Lebedeva M.I., Gorbatova E.A. Interlaboratory comparison test sinmineralogical works. Reference materials 2017. Vol. 13(2), P. 37-47. (In Russ.)]

13. Karpov I.K., Chudnenko K.V., Kulik D.A. Modeling chemical mass transfer in geochemical processes: Thermodynamic relations, conditions of equilibria, and numerical algorithms. American Journal of Science 1997. Vol. 297, P. 767-806.

14. Duran O.S., Odell P.L. Claster Analysis. A Survey. Springer-Verlag Berlin Heidelberg, New York, 1974. $140 \mathrm{p}$.

15. Гусев В.А., Карпов И.К., Киселев А.И. Алгоритм построения иерархической дендрограммы кластер-анализом в геолого-геохимических приложениях. Известия АН СССР. Серия геологическая 1974. № 8, C. 61-67. [Gusev V.A., Karpov I.K., Kiselev A.I. Algorithm for constructing a hierarchical dendrogram by cluster analysis in geological and geochemical applications. Proceedings of the USSRAcademy of Sciences. Geological series 1974. No. 8, P. 61-67. (In Russ.)]

16. Другов Г.М., Карпов И.К., Санин Б.П. Предварительная обработка геохимических данных методом кластер-анализа. Геология и геофизика 1974. Т. 169(1), C. 119-123. [Drugov G.M., Karpov I.K., Sanin B.P. Preliminary processing of geochemical data by cluster analysis. Geology and geophysics 1974. Vol. 169(1), P. 119-123. (In Russ.)]

17. Karpov I.K., Chudnenko K.V., Kulik D.A., Avchenko O.V., Bychinskii V.A. Minimization of Gibbs Free Energy in Geochemical Systems by Convex Programming. Geochemistry International 2001. Vol. 39(11), P. 1108-1119.

18. Чудненко К.В. Термодинамическое моделирование в геохимии: теория, алгоритмы, программное обеспечение, приложения. Новосибирск: Гео, 2010. 287 с. [Chudnenko K.V. Thermodynamic modeling in Geochemistry: theory, algorithms, software, applications. Novosibirsk, Geo, 2010. 287 p. (In Russ.)]

19. Helgeson H.C., Delany J.M., Nesbitt H.W., Bird D.K. Summary and critique of the thermodynamic properties of rock-forming minerals. Amerian Journal of Science 1978. Vol. 278-A, P. 1-229.

20. Yokokawa $\mathrm{H}$. Tables of thermodynamic properties of inorganic compounds. Journal of the national chemical laboratory for industry 1988. Vol. 83, P. 27-118.

21. Карпов И.К., Киселев А.И., Летников Ф.А. Моделирование природного минералообразования на ЭВМ. М.: Недра, 1976. 256 с. [Karpov I.K., Kiselev A.I., Letnikov F.A. Computer simulation of natural mineral formation. Moscow: Nedra, 1976. 256 p. (In Russ.)]

$$
-76-
$$


22. Stefánsson A. Dissolution of primary minerals of basalt in natural waters. I. Calculation of mineral solubilities from $0{ }^{\circ} \mathrm{C}$ to $350{ }^{\circ} \mathrm{C}$. Chemical Geology 2001. Vol. 172(3-4), P. 225-250.

23. Nriagu J.O. Environmental biogeochemistry. V. 1: Carbon, nitrogen, phosphorus, sulfur and selenium cycles. V. 2: Metals transfer and ecological mass balances. Ann Arbor Science Publisher. 1976. $797 \mathrm{p}$.

24. Ощепкова А.В., Кузьмин М.И., Бычинский В.А. Реконструкция минерального состава глубоководных байкальских осадков на основе их химического состава. Известия Иркутского государственного университета. Серия «Науки о Земле» 2013. Т. 6(1), С. 122-132. [Oshhepkova A.V., Kuz'min M.I., Bychinskij V.A. Reconstruction of mineral composition of deep-sea Baikal sediments on the basis of their chemical composition. Proceedings of Irkutsk state University. Series "Earth Sciences" 2013. Vol. 6(1), P. 122-132. (In Russ.)]

25. Oshchepkova A.V., Kuz'min M.I., Bychinskij V.A., Solotchina Je.P., Chudnenko K.V. Models of solid solutions for calculation of the mineral composition of Lake Baikal bottom sediments: A new approach to paleoclimatic reconstructions. Doklady Earth Sciences 2015. Vol. 461(2), P. 364-367.

26. Bychinsky V.A., Koroleva O.N., Oshchepkova A.V., Shtenberg M.V. Methods of determining thermodynamic properties of substances for studying natural and technological processes by the physical-chemical modeling methods. Bulletin of the Tomsk Polytechnic University. Geo Assets Engineering 2018. Vol. 329 (5), P. 48-56.

27. Smelyy R.V., Kaneva E.V., Oshchepkova A.V., Bychinskii V.A., Aisueva T.S., Shchetnikov A.A., Pashkova G.V, Yakimov I.S., Finkelshtein A.L. Determination of the mineral composition of the lake bottom sediments by x-ray diffraction method and physico-chemical modeling. J. Sib. Fed. Univ. Chem. 2019. Vol. 12(3), P. 382-394. 